\title{
AQUA-TNET Thematic Network: an 18-year chronicle of development and achievement in European aquaculture
}

education

\section{Authors}

Margaret Eleftheriou 1

Marieke Reuver ${ }^{2}$

John Bostock ${ }^{3}$

Patrick Sorgeloos 4

Jean Dhont 4

${ }^{1}$ AQUALEX Multimedia Consortium Ltd, Dublin, Ireland margaret@hcmr.gr

${ }^{2} \mathrm{AQUATT}$, Dublin, Ireland marieke@aquatt.ie

${ }^{3}$ Institute of Aquaculture, University of Stirling, Stirling, FK9 4LA, UK j.c.bostock@stir.ac.uk

${ }^{4}$ Laboratory of Aquaculture and Artemia Reference Centre, Ghent, Belgium, Patrick.Sorgeloos@ugent.be, Jean.Dhont@UGent.be

\section{ABSTRACT}

The long-running higher education network AQUA-TNET, a tightly-knit collaboration of university departments, research institutes and other stakeholders from the aquaculture industry, was established in 1996 by AQUATT, a coordinating partner in the SOCRATES-ERASMUS Thematic Network DEMETER led by ICA (Association for European Life Sciences Universities). Later AQUA-TNET activities continued 
under the umbrella organisation, the AFANET Thematic Network. Previous work on accreditation in European aquaculture courses carried out by AQUA-TNET's first coordinator, the UETP (Irish University Enterprise Training Partnership) AQUATT enabled the fledging network of 15 partners to publish details of aquaculture courses in all its 15 member countries and to focus on issues soon to be raised as part of the emergent Bologna Process (1999). AQUA-TNET's ground-breaking work in educational reforms led to its steady expansion, with the result that in 2005 it was established as a stand-alone ERASMUS Thematic Network. Its achievements from 2005 to 2011 under the coordination of Ghent University (Belgium) and from 2011 to 2014 by the University of Stirling (UK), demonstrate the incremental impact of AQUATNET's long-term activities. AQUA-TNET played a leading co-operative role between higher education institutions, further education providers, research institutions and industry, defining and developing a high-quality European dimension within its academic disciplines.

Activities included contributions to Bologna priorities such as student and staff mobility (M.Sc. and Ph.D. online portals detailing all members' courses); development of innovative M.Sc., Ph.D., HE/VET and LLL programmes; organisation of hands-on workshops on new technologies (e-learning, ICT); identification of flexible pathways for life-long learners (EQF and ECVET); developing diversified language learning for HE; excellent online forum (www.aquatnet.com) disseminating comprehensive information to all stakeholders, including industry.

\section{KEYWORDS}

Aquaculture; aquatic resources management; Ph.D. programmes; disparity in M.Sc. courses; Early Stage Researchers; Education Portal; flexible learning pathways; 
distance learning; student mobility; ICT hands-on workshops; mutual accreditation; university enterprise training partnership; Diploma Supplement; ECTS; ECVET; language learning and linguistic diversity; aquaculture stakeholder fora; AQUA-TNET newsletter

\section{ABBREVIATIONS}

EAS - European Aquaculture Society

EAS (SG) - European Aquaculture Society Student Group

EATIP - European Aquaculture Technology and Innovation Platform

ECTS - European Credit Transfer System

ECVET - European Credit system for Vocational Education and

Training

EHEA - European Higher Education Area

EQF - European Qualifications Framework

ERA - European Research AREA

EUA - European Universities Association

FORCE - Action Programme for the development of continuing vocational training in the European Community

HE - Higher Education

LLP - Lifelong Learning Programme

UETP - University Enterprise Training Partnership

VET - Vocational Education and Training 


\section{BACKGROUND}

AQUA-TNET, a multidisciplinary Thematic Network in the field of aquaculture, fisheries and aquatic resources management, is a tightly-knit collaboration of university departments, research institutes and stakeholders from the aquaculture industry.

Founded originally in 1996 as the aquaculture branch of the SOCRATES-ERASMUS Thematic Network DEMETER, it was coordinated by the Irish not-for-profit company AQUATT. As early as 1993, AQUATT in its capacity as the first aquaculture training and technology transfer University Enterprise Training Partnership (UETP) had noted the lack of reliable certification and mutual accreditation awarded to certain important tertiary aquaculture courses. These concerns led to its commissioning a survey and subsequent report as part of an EU FORCE project, "Framework for Future Mutual Recognition of Aquaculture throughout Europe" (Eleftheriou 1996), which scrutinized the course provision of tertiary aquaculture courses in four important aquaculture industry countries (Norway, France, Ireland, Scotland) in depth and in detail. This revealed not only the proliferation of courses but also the significant differences in course content and duration, assessment instruments used, as well as the methods used to quantify and indicate the quality of the degree/ certificate/qualification obtained. This public and open description of these significant differences paved the way for a new, more transparent discourse between the players and led to the creation of a unique database of comparative data on aquaculture course provision in higher education.

Thus, in 1996, when the first AQUA-TNET network of fifteen partners was set up in partnership with DEMETER, the agricultural, forestry and aquaculture Thematic 
Network, AQUATT as the coordinating partner for aquaculture envisaged that its main purpose was to set up a higher education forum focusing on issues such as:

- control of curriculum content and delivery

- the mutual acceptance of degrees (mutual recognition and accreditation)

- mobility of trainers and students

- strong industry-university co-operation (through internships and fieldwork for Master/Ph.D. thesis).

Well before the onset of the Bologna Process (1999), the AQUA-TNET network established working groups with the following objectives:

a) to assess, compare and analyse the state of the aquaculture tertiary education sector in Europe

b) to identify key curricular development objectives

c) to produce and disseminate a review of best practice in European tertiary education

d) to move towards a more open, transparent and innovative system of course provision and assessment

e) to review and facilitate aquaculture staff and student mobility.

The original fifteen AQUA-TNET partners were able to make use of the information in the area of comparability and mutual accreditation of course work and certification which had been collected and compiled in the afore-mentioned FORCE Mutual Accreditation Survey. New AQUA-TNET activities were thus able to extend the scope of the earlier dataset collected from Ireland, Scotland, Norway and Greece, to all fifteen AQUA-TNET partners. This led to AQUA-TNET's first publication, "Higher Education in Aquaculture and Related Sciences - Guide to Courses within Europe" (Fitzgerald et al. 1998). This publication, the first of its kind in aquaculture, listed all academic aquaculture course units/modules and courses in each participating country 
(Belgium, Denmark, Finland, France, Germany, Greece, Iceland, Ireland, Italy, The Netherlands, Norway, Spain, Portugal, Sweden and the UK) All information was presented in a comparable format, in conformity with the EURYDICE (1996) recommendations (in effect anticipating the UNESCO Diploma Supplement Initiative (European Commission, Council of Europe and UNESCO/CEPES 1999) which four years later became an integral part of the Bologna Process in the Berlin Ministerial Communiqué (Berlin 2003). The diversity of aquaculture courses in European academic institutions became all too visible, pre-dating by four years a phenomenon that was also highlighted in the European Universities Association (EUA) publication "Survey on Master Degrees and Joint Degrees in Europe" (Tauch and Rausvargers 2002).

\section{Merger with AFANET partnership (1998 - 2004)}

In 1998, the AQUA-TNET and DEMETER Thematic Networks were amalgamated into a new SOCRATES-ERASMUS network, the AFANET Thematic Network (Agriculture, Forestry and Aquaculture), a phase which lasted until 2004. Though financial constraints within AFANET limited AQUA-TNET activities to the development of tools enabling the implementation of the Diploma Supplement (eventually becoming part of the restructured EUROPASS in 2004), the AQUA-TNET partners continued to address the long-term education and training needs of the European aquaculture industry, with the "White Paper on Education and Training in Aquaculture for the New Millennium" (Owen et al 2000). Published in 2000 and 2005, the White Paper, again anticipating the Bologna Process, made formal recommendations covering the following areas:

- the promotion of geographic and functional mobility

- transnational placements at various levels (post-grad and post-doc) 
- exchanges of trainers between countries and organisations

- the delivery of highly specialised and advanced education and training

- joint development of specific specialised courses

- accreditation and mutual recognition of qualifications.

\section{From AFANET partnership to stand-alone Thematic Network}

AQUA-TNET's genuinely ground-breaking work in educational reforms had led to its steady expansion, with the result that in 2005 it broke away from the AFANET Thematic Network to become the largest multidisciplinary European Education Network in the field of aquaculture, fisheries and aquatic resources management. The incremental impact of the measures recommended by each phase of AQUA-TNET can be seen in the subsequent activities of the network. However, as the second stage of the EU educational programme SOCRATES II, stipulated that ERASMUS Thematic Networks (TNs) had to be coordinated by an academic institution, AQUATT as a notfor-profit company relinquished its role as coordinator of the network, while retaining an executive and management role. AQUA-TNET continued to progress under new coordinators, firstly Ghent University (Belgium) from 2005 to 2011 and then the University of Stirling (UK) from 2011 to 2014. AQUA-TNET extended its leading cooperative role between higher education institutions and other partners such as further education providers, research institutions and industry, aiming to define and develop a quality European dimension within its various academic disciplines. Its achievements in many of its areas of activities are described in the other articles in this Special Issue of Aquaculture International. 


\section{AQUA-TNET (SOCRATES 225997-CP 1-2005-1-FR-ERASMUS-TN)}

AQUA-TNET (October 2005 - September 2008) with 109 partners representing universities, training organisations, associations and research performers working in aquaculture, fisheries and aquatic resource management, coordinated by Ghent University, Belgium, was specifically set up to unite the academic and vocational aspects of the Bologna reforms and to support the establishment of the European Higher Education Area in the field of Aquaculture, Fisheries and Aquatic Resources Management. Other important objectives were:

- to contribute to including Life Long Learning in the new Qualifications Frameworks

- to provide access to the latest developments in e-learning

- to help integrate new member states and other $3^{\text {rd }}$ party countries

- to implement the EU recommendations for language learning in higher education

- to foster a substantial increase in student and staff mobility

- to map the European Aquaculture by competencies

- to draw together Education and Research, to pool resources from EC funded Education Initiatives

- to provide a forum for all stakeholders to have input into the development of the workforce in order to develop a sustainable aquaculture sector.

To carry out these challenging objectives, six thematic areas were the focus of the AQUA-TNET Action Plan, organised to run throughout the three years of the project. These areas were as follows:

- M.Sc. curriculum development and assessment 
- Ph.D. curriculum development and assessment

- proposed transparency measures (including Qualifications Frameworks) and Quality Assurance

- measures to improve student mobility

- innovation in teaching (e-learning and ICT technologies and their role in joint degrees)

- new methods of language training and the promotion of language diversity.

The AQUA-TNET network played a crucial role in bringing together all types of stakeholders in the maritime sector, encouraging the best use of results, innovative products and processes, exchanging good practice in order to improve the quality of education and training in the sector. The flow of information and knowledge transfer to external users added value to the network which raised awareness of the Bologna reforms not only in academia but also succeeded in gaining support from other stakeholders. Its innovative Stakeholder work package involved industry, consumers, research and students; representatives of the industry, students and consumers were invited to play an active role in the network, such as participating in the formulation of the work programme, making informed assessments of the project's progress and the relevance of the results, disseminating among their peers, etc. Both in AQUA-TNET 2 and AQUA-TNET 3, dedicated work packages were set up to maximise the involvement of stakeholders in the ongoing processes.

While involving consumers proved to be less successful than expected, the student and industry communities rapidly developed a vivid interest in various AQUA-TNET activities and each group became an integral partner in the network. Starting in AQUATNET 2, students and industry representatives participated in and reinforced several work package teams. In this way, they added a much-appreciated perspective to issues 
such as student mobility, generic skills in education, innovation in education, and other matters. AQUA-TNET effectively stimulated the drive of the hitherto somewhat dwindling European Aquaculture Society Student Group (EAS SG) by involving EAS SG delegates in its work packages thus giving the students a voice and an active role in the network. AQUA-TNET also supported student sessions at the EAS yearly conferences for instance by organising dedicated workshops on generic skills for students. In addition, virtually all AQUA-TNET achievements have direct or indirect benefits for students: the education portal, the mobility portal, the job and training opportunity section.

Beside these active contributions, a fair number of additional stakeholders have attended AQUA-TNET's Annual Events, well-attended and well-organised events which played a strong role in the network, enhancing its impact while at the same time extending and strengthening its position beyond the sector. Industry and student stakeholders enriched discussions and provided valuable feedback from a point of view other than academic. Over the years, special attention was paid to organise the Annual Events around themes of interest to industry participants.

A significant step in the acknowledgement of AQUA-TNET as the representative body for European aquaculture higher education is its inclusion in 2012 in the European Aquaculture Technology and Innovation Platform (EATIP) knowledge transfer strategy. This commitment allowed a first-hand contribution to the new EU Integrated Maritime Policy (2013) and reflects the strength of its sectorial impact.

As the AQUA-TNET project (SOCRATES 225997-CP 1-2005-1-FR-ERASMUS-TN) neared its conclusion, there was clear evidence that Higher Education was changing rapidly, and not only because of the changes resulting from the implementation of the 
Bologna Process. Other factors, such as globalisation and the development of the Internet, were also in the process of creating new challenges and opportunities. EU policy-makers recognised the increasingly competitive nature of the global economy and the vital importance of strengthening and maintaining innovation. It was held to be a self-evident truism that innovation could be supported by improving links between research and teaching. Thus access to further and higher education was extended and a new type of infrastructure for lifelong learning was developed. EU policy-makers considered that innovation would be supported by improving collaboration across Member States. As a result, policies were put in place for improving student and teacher mobility through standardised and mutually recognised qualification frameworks; more transparent descriptions of competences achieved; and addressing barriers such as lack of quality resources in less widely spoken languages. AQUA-TNET sought to address these issues for the aquaculture and related sectors.

\section{SUCCESSIVE AQUA-TNET THEMATIC NETWORKS}

By the end of the project in September 2008, AQUA-TNET's activities had increased and so had its relevance and influence. As a result, the European Community approved co-funding for another phase of this long-running network. The network took advantage of this excellent opportunity both to consolidate its first phase activities, and also to build in new elements. The new programme allowed the network to continue its important work of helping the sectors covered to contribute to the creation of a European Higher Education Area (EHEA). The renewal also allowed the network to review priorities and activities and to make any improvements necessary to help meet the needs of all stakeholders. 


\section{AQUA-TNET 2 (142245-LLP-1-2008-1-BE-ERASMUS-ENW)}

AQUA-TNET 2 (142245-LLP-1-2008-1-BE-ERASMUS-ENW) also coordinated by Ghent University, had 120 partners from 25 countries. The aims of AQUA-TNET 2, again directly in step with the drive to strengthen the implementation of the Bologna reforms in the aquatic science sector, were:

- to contribute to the current Bologna priorities: mobility, M.Sc. and Ph.D. programmes, HE/VET \& lifelong learning

- to further enhance and promote innovative course provisions for both Bologna cycles, keeping abreast of latest developments

- to further promote the Bologna recommendations (London 2007) to include LLL in the overarching qualifications frameworks by working on mechanisms to enable partners to provide suitable lifelong learning within their systems

- to disseminate information on state-of-the-art developments in new pedagogy and technologies and quantify potential uses as flexible pathways giving life-long learners access to learning opportunities. (Council Resolution 2001/C 204/02)

- to implement the EU recommendations for language learning in higher education in the light of the Action Plan for Language Learning and Linguistic Diversity (European Commission, 2004)

- to encourage a substantial increase in student and staff mobility, both through increasing uptake of EC opportunities (Lifelong Learning Programme (LLP), Marie Curie) and improved interaction between sending and host organisations using the updated web portal 
- to strengthen communication between teaching and research (EHEA and ERA) in order to transfer ideas, knowledge and skills through research institutes taking an active part in the network

- to provide a forum for all stakeholders to have input into the development of the workforce helping to maintain a sustainable sector

At this stage in the evolution of the network, its six major thematic areas were finetuned as shown in its three-year action plan. The three curriculum-centred thematic areas remained as before (M.Sc. developments, Ph.D. course design, student mobility issues) but these were joined by new approaches as the Bologna reforms began to take effect. The new or revised thematic areas were as follows: new generic skills and competences approaches; innovation in teaching methods; positioning lifelong learning and multilingual issues in international cooperation.

AQUA-TNET 2 put considerable effort into participation of and links with its main stakeholders (research institutes, industry partners, student associations and consumers). In 2011, for instance, the Annual Event in Villamoura, Portugal, featured a workshop on "Microbial Management in Fish \& Shellfish Larviculture". This workshop attracted over 50 participants from companies and led to a lively discussion on the need for adequate training and education on this specific discipline in support of the European industry.

Much care also went into the expansion and updating of the dissemination outlets such as the dedicated website and the electronic newsletters, as illustrated below:

- Monthly Training News Newsletters (almost 6000 subscribers)

- Monthly AQUA-TNET Newsletters 
- BibMail and Information of Interest

- Dissemination events at sectoral tradeshows/conferences

- Leaflets, brochures for individual events, including Aqua-tnet Annual Events and network map

- Its very well-designed website www.aquatnet.com contains all the above, all project information, and also acts as the electronic heart of the project where: *questionnaires are set up and responses analysed

*discussion groups, open to all members, debate relevant issues

*the M.Sc., Ph.D. and Student Mobility portals are housed

*results of surveys, internal reports, core group minutes are available

*resources such as open source software for e-learning can be accessed,

*multilingual glossaries, fish health courses, language lessons are found

AQUA-TNET 2 completed substantial analyses of the current state of teaching and learning in aquaculture and fisheries (referred to in other parts of the Special Issue) and initiated several worthwhile practical collaborations.

AQUA-TNET 2 continued to support increased cooperation in European Masters, Ph.D. and Mobility by updating and maintaining a database with information about available educational programmes within the AQUA-TNET domain in Europe, the user-friendly, attractive AQUA-TNET Education Gate. It allowed searches to be made in respect of institutions, people, M.Sc. courses and programmes as well as Ph.D. courses. Similarly, the network worked towards increased cooperation in respect of $\mathrm{Ph} . \mathrm{D}$. curriculum development. The previously existing Ph.D. portal, a valuable information and research tool for AQUA-TNET members, was updated and integrated with the Master database 
portal as described above, so that the network could further enhance and promote innovative course provisions for both Bologna cycles, keeping up-to-date with the latest developments. These portals also contained a database of 280 doctoral theses which were supervised by AQUA-TNET members, as well as details of 59 doctoral programmes.

\section{AQUA-TNET 3 Promoting innovation and a European dimension through Lifelong learning in the field of Aquaculture, Fisheries and Aquatic Resources Management (518700-LLP-1-2011-1-UK- ERASMUS-ENW]}

The third AQUA-TNET (2011 - 2014) at the time of writing has 91 organizations, from 26 different countries, to consolidate this comprehensive European network for innovative lifelong learning in the field of aquaculture, fisheries and aquatic resources management. Its members are universities, institutes, student association, producers and recent technology platforms: EATiP (European Aquaculture Technology and Innovation Platform) and EFTP (European Fisheries Technology Platform). The AQUA-TNET network continues to link teachers, students, researchers, employers, employees and consumers.

The principal aim of the network in its last phase has been to support the progress of the European aquaculture, fisheries and aquatic resources management sector towards the EC policy goal of greater and sustainable output by stimulating and supporting innovation through enhanced lifelong learning opportunities. 
This aim has been furthered by means of core work packages involving smaller working groups comprised of representatives of the wider network membership. These have concentrated on producing useful outputs through collaborative actions, as follows.

WP1 (European Master Collaboration) has focused on developing online industryfocused case studies that can be used in a variety of teaching activities. These now form the core of a 5 ECTS course in European Aquaculture, supported by a range of video and other materials produced by AQUA-TNET members (AQUACASE (www.aquacase.org) which includes interactive exercises.

WP2 (European Ph.D. Collaboration) has developed and supported short specialist training courses for Ph.D. students. Using information from their Early Scientific Researcher (ESR) survey with regard to desirable new courses, the doctoral team organised the course "Microbial management in aquaculture" 1 in the University of Gent in August 2012. The 3-day course for young researchers (ESRs) provided information concerning recent developments in microbial management in larviculture, and how to generate and process microbial community data. Pedagogic methods: traditional classic lectures; micro-teaching (peer to peer); preparation of Powerpoint presentations in small peer groups; ICT tools training (theoretical and hands-on). The course (2 ECT credits) was taken by 30 students and involved 12 teachers, including experts from the industry.

WP3 (AQUA-TNET on the move (Mobility)) has further developed the AQUA-TNET Education Gate Internet Portal service and enhanced the guidelines for providers and users of mobility activities.

WP4 (Generic skills for future success) has conducted research on training needs and responded with the production of three generic skill training packages in project management, data management and presenting research findings.

\footnotetext{
${ }^{1}$ http://www.promicrobe.ugent.be/Public/Agenda/Workshop.html (accessed 21/07/2014)
} 
WP5 (Innovating Lifelong Learning) has worked on several areas including a) Annual Event workshop on flexible learning pathways relevant for the sector, based on the successful Malta Qualifications Authority case study on how to create articulation between the VET and HE qualification frameworks ; b) curricular frameworks and the implementation of transparency in qualifications, with especial regard to the European Universities Charter on Lifelong Learning and its implementation; and c) digital teaching skills including the organisation of a 2-day training workshop for members which also took place at the 2014 Annual Event in Malta. The topics for training were: video production; audio production; e-portfolios for students; sharing presentations; how to use social media. All topics were accompanied by excellent training manuals which can be found at http://www.aquatnet.com/index.php/218/ict-workshop/ WP 6 (Stakeholder Cooperation) coordinated the input of different stakeholders to identify priorities and exploitable outcomes. WP 7 (Dissemination and Outreach) has made increasing use of social media in addition to its long-term and ongoing dissemination channels (http://www.aquatnet.com/index.php/60/news/). WP 9 (Quality Assurance) has assured that all deliverables from this last phase of the network are of suitably high quality.

\section{End note}

Over the past eighteen years, all AQUA-TNET projects have provided valuable services for dissemination results and essential information. The network has conducted its business and developed its deliverables by means of core group meetings convened by WP leaders, work package discussions taking place via email or internet conferencing and through dedicated WP website pages. An Annual Event was organised almost every year, where progress was reported, deliverables were demonstrated and evaluated, and 
future targets were set for all members as well as core groups and stakeholder representatives. In addition, much investigative effort has been expended over the years on gathering data in the form of needs analyses (latterly completed electronically, thus eliminating much of the tedium normally associated with this task) relevant to each of the designated work packages. These data have generated several valuable and comprehensive reports concerning M.Sc. and Ph.D. courses, the use of new tools and technologies in teaching, generic skills and student mobility needs. The AQUA-TNET database of European aquaculture and marine science courses (Education Gate) has been a much-used resource, for both staff and students alike. This portal gives details of Master courses currently running throughout the entire network, and links to Ph.D. theses and presentations from students within the network. The entire multilingual resources of the PESCALEX website (www.pescalex.org) have been made freely available. In addition, European teaching staff have been able to exchange experiences and incorporate the latest research findings into their teaching which leads to students becoming aware of the latest techniques which can facilitate their entrance into the workforce.

Without the prospect of further funding for Thematic Networks in the EU ERASMUS + Programme, it is anticipated that some of the network's very successful initiatives and activities will continue, albeit with specific core group partners, looking to find funding from alternative international and national sources. Opportunities will be found to continue with the wide-ranging issues involved in knowledge management gained from its experience in the current and past AQUA-TNET projects. In addition, AQUA-TNET has been pointed out by FAO (2011) as "a pan-European education network (which) is considered another good model on networking which could be adopted by other regions". In the meantime, AQUATT, the original founding member of the network, 
will continue to host AQUA-TNET services and assets, many of which the company initiated, developed or hosted over the years, including the Education Gate portal containing essential information on aquatic science organisations, the courses that they run and the student mobility opportunities that exist.

\section{Acknowledgements}

The authors would like to thank those who helped to set up and run the network: Richard Fitzgerald, Michael Thomson, Melanie Mercer, Gavin Burnell and David Murphy.

\section{References}

Berlin (2003) Realising the European Higher Education Area: Communiqué of the Conference of Ministers responsible for Higher Education, 19 September 2003. http://www.ehea.info/Uploads/Declarations/Berlin Communique1.pdf

Council of Europe, 2001. Common European Framework of Reference for Languages: Learning, Teaching, Assessment. Cambridge University Press. Online Document (updated in 2008/09); http://www.coe.int/t/dg4/linguistic/Source/Framework_EN.pdf

Eleftheriou M (1996) "Framework for Future Mutual Recognition of Aquaculture throughout Europe", AQUATT, Dublin, 64p www.researchgate.net/profile/Margaret_Eleftheriou/contributions?ev=prf_act 
European Commission 1999

European Commission (2003) Communication from the Commission to the Council, the European Parliament, the Economic and Social Committee, and the Committee of the Regions. Promoting Language Learning and Linguistic Diversity: An Action Plan 2004-2006, $\operatorname{COM}(2003) 449$ final.

http://ec.europa.eu/education/doc/official/keydoc/actlang/act_lang_en.pdf

European Council (2004) Decision No 2241/2004/EC of the European Parliament and of the Council of 15 December 2004 on a single Community framework for the transparency of qualifications and competences (EUROPASS)

EURYDICE (1996) Key data on Education in the European Union, $2^{\text {nd }}$ edition,

FAO, 2011. World aquaculture 2010. FAO Fisheries and Aquaculture Department. Technical Paper $500 \quad$ (1). Rome, $\quad$ FAO. 105 pp. http://www.fao.org/docrep/014/ba0132e/ba0132e00.htm

Fitzgerald R., Mercer M and Hobbs C (1998) Higher Education in Aquaculture and Related Studies: Guide to Courses within Europe. Eds: Dublin, 1998.

London (2007) Towards the European Higher Education Area: responding to challenges in a globalized world. Communiqué of the Conference of European Ministers Responsible for Higher Education, London: May 18, 2007.

Owen L. Fitzgerald R. and Eleftheriou M (2000) "White Paper on Education and Training in Aquaculture for the New Millennium”, AQUATT, Dublin. 87p. 
https://www.researchgate.net/profile/Margaret_Eleftheriou/publications?pubType=book $\underline{\text { \&ev }=\text { prf_pubs_book }}$

Tauch C and Rauhvargers A (2002) "Survey on Master Degrees and Joint Degrees in Europe”. European Universities Association, Brussels. 45p.

http://www.eua.be/eua/jsp/en/upload/survey_master_joint_degrees_en.1068806054837. pdf 